Çukurova Üniversitesi Mühendislik Mimarlık Fakültesi Dergisi, 35(3), ss. 609-622, Eylül 2020

Cukurova University Journal of the Faculty of Engineering and Architecture, 35(3), pp. 609-622, September 2020

\title{
Basit Mesnetli Köprülerde Hareketli Yük Dağılım Faktörleri Denklemlerinin Yapay Sinir Ağları ile Elde Edilmesi
}

\author{
Ö. Fatih YALÇIN ${ }^{* 1}$ \\ ${ }^{1}$ İstanbul Üniversitesi-Cerrahpaşa, Mühendislik Fakültesi, İnşaat Mühendisliği Bölümü, \\ Istanbul
}

Geliş tarihi: 17.04.2020

Kabul tarihi: 23.10 .2020

$\ddot{\mathbf{O z}}$

Yapay zekâ konusunda kaydedilen ilerlemeler günümüzde her alanda çok önemli dönüşümlere neden olmaktadır. İnşaat mühendisliği alanında da yapay zekâ, makine öğrenmesi ve yapay sinir ağları uygulamaları ve kullanımı her geçen gün artmakta ve çeşitlenmektedir. Bu gelişmelere paralel olarak, bu çalışmada, yapay sinir ağları kullanılarak köprü tasarımında kullanılan hareketli yüklerin köprü kirişlerine dağılımı için kapalı formüller elde edilmiştir. Bu formüllerde, farklı yapısal köprü parametrelerinin yanı sıra, AASHTO LRFD'de verilen denklemlerde dahil edilmemiş olan kiriş sayısı parametresi de eklenmiştir. Bu amaçla, birçok verevsiz basit mesnetli köprü modeli hazırlanarak olası tüm kamyon yükleri altında sonlu elemanlar analizleri yapılmış ve hareketli yük dağılım katsayıları elde edilmiştir. Yapay sinir ağları ile elde edilen hareketli yük dağılım faktörleri, sonlu elemanlar analiz sonuçları ile ve AASHTO LRFD'de verilmiş olan hareketli yük dağılım katsayıları ile karş̧laştırılmış̧ır. Bu karşılaştırmalar göstermektedir ki, sinir ağları ile elde edilen formüller dağılım faktörlerini oldukça iyi tahmin edebilmektedir.

Anahtar Kelimeler: Yapay zekâ, Yapay sinir ağları, Köprüler, Hareketli yük, Dağılım faktörleri

\section{Obtaining Live Load Distribution Factors Equations for Simply Supported Bridges Using Neural Networks}

\begin{abstract}
Advancements in artificial intelligence have caused important transformations in many areas. Research on applications of artificial intelligence, machine-learning and neural networks in civil engineering has been growing recently. Parallel to this progress, in this study, closed-form formulas for distribution of live load among the bridge girders are obtained using artificial neural networks. In these formulas, the number of girders is also incorporated as a new parameter, which is not included in AASHTO LRFD live load distribution equations. For this purpose, numerous straight, simply supported bridge models are analyzed using the finite element method and subsequently live load distribution factors are calculated. Live load distribution factors obtained through neural networks are compared with those from finite element analyses and AASHTO LRFD formulas. These comparisons reveal that closed-form formulas can predict live load distribution factors accurately.
\end{abstract}

Keywords: Artificial intelligence, Neural networks, Bridges, Live load, Load distribution

*Sorumlu yazar (Corresponding author): Ö. Fatih YALÇIN, fyalcin@ gmail.com 


\section{GíRiş}

Yapay zekâ örüntüleri tanımlamak, regresyon, kümeleme ve sınıflandırma gibi işlemleri yapmak için tasarlanmış bir tür hesaplama algoritmasıdır. $\mathrm{Bu}$ algoritma "nöron" olarak adlandırılan biyolojik sistemlerden esinlenilerek geliştirilmiştir ve biyolojik sistemlerden ayrıştırmak için "Yapay Sinir Ağları" (YSA) olarak adlandırılmıştır. $\mathrm{Bu}$ algoritmalar kullanılarak konuşma tanımlama, görsel cisim tanımlama ve cisim algılama gibi ileri teknoloji alanlarında çok önemli gelişmeler kaydedilmiştir [1]. Bunların yanı sıra, yapay zekâ uygulamaları bir takım mühendislik problemlerinin çözümünde insan algılamasını simüle edebilme imkânı ile klasik mühendislik yöntemlerine meydan okumaktadır. Hatta uygulamalar o kadar ileri gitmiştir ki, Tshitoyan ve arkadaşları [2] malzeme bilimi konusundaki literatürde yapılan tüm çalışmaları sadece dili kullanarak tarayabilen bir yapay zekâ uygulaması geliştirmişlerdir. Bu uygulama aracılığ 1 ile milyonlarca bilimsel makale özeti taranarak kelimeler incelenmiş ve malzemelerin farklı özellikleri ile ilgili araştırmacıların henüz bulamadığı gizli kalmış ilişkiler yakalanmış ve yeni buluşlar yapılmıştır.

Yapay zekâ yöntemleri tüm mühendislik alanlarında olduğu gibi inşaat mühendisliği alanında da önemli uygulama alanları bulmaya devam etmektedir. Örneğin, geoteknik mühendisliği alanı, toprak kaya gibi davranışı çok kesin olmayan ve klasik fiziksel modelleme yöntemlerini zorlayan malzeme davranışı ile ilgilidir. Yapay zekâ yöntemleri de bu tür karmaşık ilişki ağlarını çözmeye çok uygun olduğu için, sıvılaşmadan kazıklara, barajlardan tünellere kadar geotekniğin her alanında uygulama alanı bulmuştur [3,4]. Yapı mühendisliği alanı da yapay zekânın en geniş kapsamda yer bulduğu alanlardan birisidir [5], özellikle de yap1 sağlığı izlemesi [6], yap1 davranışı $[7,8]$, betonun karakterizasyonu $[9,10]$ ve deprem mühendisliği [11] konularına araştırmacılar yoğunlaşmışlardır.
İnşaat mühendisliğindeki çok güçlü tasarım pratiklerinin uygulandığı köprü mühendisliğinde de yapay zekâ uygulamaları yer edinmiştir. Özellikle köprü sağlığı izleme [12], köprü muayenesi [13], köprü bileşenlerinin davranış1 [14] ve tasarımı $[15,16]$ alanlarında bu uygulamalar görülebilir.

$\mathrm{Bu}$ çalışmada da köprülerdeki kamyon yüklerinin kirişler üzerindeki etkileri, hareketli yük analizleri ve yapay sinir ağları kullanılarak formüle edilecektir. Karayolu köprülerinin karmaşık 3Boyutlu (3B) sonlu elemanlar modelleri ile analizi mümkün olmakla birlikte, tasarım ofislerinde bu modelleri her köprü için yeniden oluşturmak ve tüm yükleme kombinasyonlarını hazırlamak zaman alıcı olacaktır. $\mathrm{Bu}$ nedenle tasarım mühendisleri, 3B modeller yerine AASHTO LRFD [17] yönetmeliğinde ve diğer yabancı ülkelerin yönetmeliklerinde verilen Hareketli Yük Dağılım Katsayılarını (HYDK) ve 2-Boyutlu (2B) yapısal modelleri kullanmaktadırlar. HYDK kullanılarak, hareketli yükler altında köprü kirişlerindeki maksimum moment veya kesme, tek kamyon yükü altında 2B modelden elde edilen maksimum moment veya kesmenin HYDK ile çarpılması ile bulunabilir.

AASHTO LRFD yönetmeliğinde tanımlanan bu faktörlere ait denklemler, köprünün yapısal özelliklerine bağlı olarak formüle edilmişlerdir. Bahsi geçen denklemler Zokai ve arkadaşları [18] tarafından NCHRP 12-26 projesi altında geliştirilirken, bu karakteristik özelliklerin içerisinde köprü genişliğini etkileyen kiriş sayısı $(\mathrm{Nb})$ ise dahil edilmemiştir. Ancak Yalcin ve Dicleli [19] yaptıkları çalışmalarda kiriş sayısının HYDK'yi yaklaşık \%5 oranında etkilediklerini bulmuşlardır. Bu nedenle bu çalışmada yapay sinir ağları kullanılarak, AASHTO LRFD'de verilen HYDK denklemlerinin köprüdeki kiriş sayısı $(\mathrm{Nb})$ parametresi de dahil edilerek kapalı formda ifadeleri elde edilmiştir. Literatürde köprülerdeki hareketli yük etkilerinin yapay zekâ kullanılarak tahmini ile ilgili çalışmalara rastlanmamıştır. Bu nedenle, bu çalışma özgün ve güncel niteliklere sahiptir. 


\section{BASITT MESNETLİ KÖPRÜLER}

Çalışma kapsamında farklı yapısal parametrelere sahip birçok basit mesnetli köprü modeli SAP2000 [20] sonlu elemanlar yazılımı kullanılarak oluşturulmuştur. Hareketli yük dağılım faktörlerini elde edebilmek için bu köprülerin hem 3 boyutlu (3B) (Şekil 1a) hem de 2 boyutlu (2B) (Şekil 1b) modelleri oluşturulmuş ve farklı kamyon yükleme yerleşimleri ve kombinasyonları altında analizler gerçekleştirilmiştir.

Ele alınan köprüler tek açıklıklı, verevsiz, simetrik ve kiriş üzerine yerleştirilen tabliye şeklindeki köprülerdir. Köprü kirişlerinin AASHTO tipi (Kiriş Tipi II-V) öngermeli beton kirişler olduğu varsayılmıştır. 3B modelde tabliye kabuk elemanlar olarak ve kirişler kiriş eleman olarak modellenmiştir. Kamyon tekerlek yüklerinin otomatik yerleştirilmesini kolaylaştırmak amacıyla tabliye $0,6 \mathrm{~m}$ kenar uzunluğuna sahip kare elemanlara bölünmüştür. Tabliyenin mesnetlere oturduğu uçlara çerçeve eleman olarak modellenmiş diyaframlar eklenmiştir. Her 3B modele karşılık gelen 2B model ise basit mesnetli ve tek kirişli bir yapı olarak modellenmiştir (Şekil 1b). 2B modelde, kirişin üzerine tabliyeyi temsil etmesi bakımından, kiriş aralığı kadar genişliğe sahip bir tabliye şeridi göz önüne alınmıştır. Tüm yapısal modellerde kiriş ve tabliyenin kompozit olarak davrandıkları varsayılmıştır.

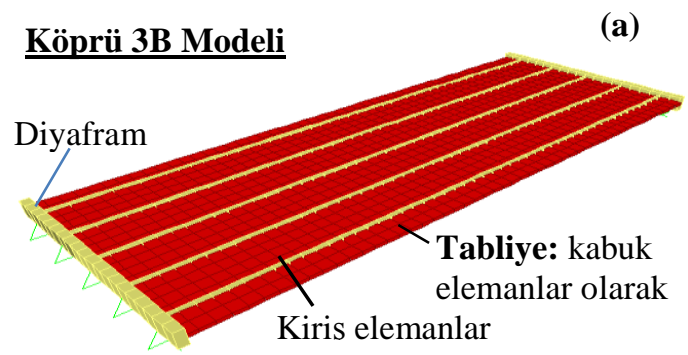

Köprü 2B Modeli

(b)

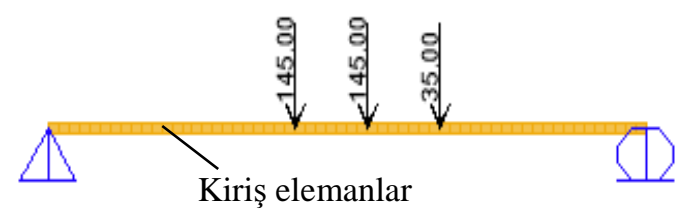

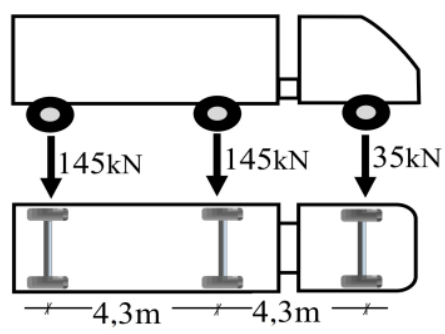

(c)

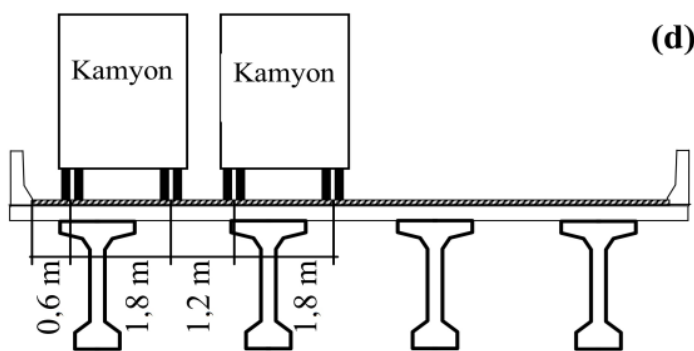

Şekil 1. (a) Basit mesnetli köprünün 3B sonlu elemanlar modeli (b) 2B sonlu elemanlar modeli (c) AASHTO LRFD, HL-93 tasarım kamyon yükü (d) Köprü üzerinde yan yana yerleştirilmiş kamyonlar için minimum mesafeler

\subsection{Hareketli Yük Modeli}

Oluşturulan 3B ve 2B yapısal modellerin sonlu elemanlar analizleri AASHTO LRFD [17] tasarım hareketli yükü olan HL-93 yükü altında gerçekleştirilmiştir. HL-93 yükü tandem ve kamyon yüklerinin kombinasyonundan oluşmaktadır, ancak HYDK denklemlerinin geliştirilmesinde sadece kamyon yükleri ele alındığ 1 için, bu çalışmada tandem yükler göz ardı edilmiştir.

Köprü bileşenleri üzerinde oluşan maksimum etkiler (moment veya kesme), tasarım kamyonunun köprü üzerinde hem enine hem de dikine yönde konumuna; yüklü olan şerit adedine ve çoklu kamyon yüklemesi çarpanına bağlıdır. HL-93 yüklemesinde ele alınan kamyon dingil yükleri ve çoklu kamyon yerleştirilmesi durumunda göz önüne alınacak açıklıklar Şekil 1c ve 1d'de sırasıyla gösterilmiştir. Uzunlamasına yönde maksimum etkileri oluşturan kamyon yerleşimi, basit mesnetli bir kirişin tesir çizgisi analizleri sonucu elde edilen lokasyonuna yakın 
çıkmaktadır. Ancak köprünün enine yönünde maksimum etkileri bulmak için bir veya birden fazla kamyonun köprü eni doğrultusunda tüm olası konumlarını incelemek gerekmektedir. Bu işlem el ile yapıldığı takdirde çok yorucu ve zaman alıcı olacaktır. $\mathrm{Bu}$ nedenle, tüm yükleme kombinasyonlar1, SAP2000 OAPI (uygulama programlama arayüzü) kullanılarak yapılmıştır.

AASHTO LRFD'de HYDK denklemleri iç ve dış kirişler için ve bir kamyon veya birden fazla kamyon yükleme durumları için ayrı ayrı verilmiştir (Çizelge 1). Sonlu elemanlar analizlerinden HYDK' yı bulmak için, 3B modeller üzerinde bir kamyon veya birden fazla kamyon (2, 3, 4 kamyon vs.) yükü altında, 2B modellerde de ise tek kamyon yüklemesi altında maksimum moment veya kesme etkileri bulunur. Dağılım katsayıları da Eşitlik 1'de moment etkisi için gösterildiği gibi, 3B detaylı analizden elde edilen maksimum etkilerin 2B analizden elde edilenlere bölünmesi sonucunda bulunur:

$$
\mathrm{HYDK}=M_{3 \mathrm{~B}} / M_{2 \mathrm{~B}}
$$

Çizelge 1. AAHSTO LRFD hareketli yük dağılım denklemleri

\begin{tabular}{|c|c|c|}
\hline & İç Kiriș & Dıș Kiriș \\
\hline $\begin{array}{c}\text { Moment } \\
\text { (Bir Șerit) }\end{array}$ & $0,06+\left(\frac{S}{4300}\right)^{0.4}\left(\frac{S}{L}\right)^{0,3}\left(\frac{K_{g}}{L t_{s}^{3}}\right)^{0,1}$ & Kaldıraç Kuralı \\
\hline $\begin{array}{c}\text { Moment } \\
\text { (Iki veya } \\
\text { daha fazla } \\
\text { şerit) }\end{array}$ & $0,075+\left(\frac{S}{2900}\right)^{0,6}\left(\frac{S}{L}\right)^{0.2}\left(\frac{K_{g}}{L t_{s}^{3}}\right)$ & $\begin{array}{l}g=e g_{i \zeta} \\
e=0,77+\frac{d_{e}}{2800}\end{array}$ \\
\hline $\begin{array}{c}\text { Kesme } \\
\text { (Bir Şerit) }\end{array}$ & $0,36+\frac{S}{7600}$ & Kaldıraç Kuralı \\
\hline $\begin{array}{c}\text { Kesme } \\
\text { (İki veya } \\
\text { daha fazla } \\
\text { şerit) }\end{array}$ & $0,2+\frac{S}{3600}-\left(\frac{S}{10700}\right)^{0,2}$ & $\begin{array}{l}g=e g_{i \zeta} \\
e=0.6+\frac{d_{e}}{3000}\end{array}$ \\
\hline
\end{tabular}

\subsection{Köprü Parametreleri}

Köprü kirişlerinin HYDK'yi etkileyen parametreleri şu şekilde sıralanabilir: kiriş sayısı $(\mathrm{Nb})$, köprü uzunluğu (L), tabliye kalınlığı (ts), kirişler arasındaki açıklık (S) ve kiriș tipi (GT). Köprülerde konsol uzunluğu (de) sabit ve $0,3 \mathrm{~m}$ olarak alınmıştır. Öngermeli kirişlerin dayanımı 50 $\mathrm{MPa}$ ve tabliye betonunun dayanımı da $30 \mathrm{MPa}$ olarak alınmıştır. Ele alınan köprü parametreleri Çizelge 2'de verilmiştir. Çizelgede gösterilen parametreler kullanılarak oluşturulan $3 \mathrm{~B}$ ve $2 \mathrm{~B}$ köprülerin tüm gerekli yükleme durumları altında analizleri yapılmış ve elde edilen iç ve dış kirişlere ait momentler ve kesme kuvvetleri için HYDK elde edilmiştir.

\section{YAPAY SIINİR AĞLARI}

Bir yapay sinir ağı insan nöronlarının davranışına benzetilmiş bir makine öğrenmesi (machine learning) algoritması olarak da tarif edilebilir.

Çizelge 2. Analizlerde kullanılan köprülere ait parametreler

\begin{tabular}{|c|c|c|c|c|}
\hline$N_{\mathrm{b}}$ & $\begin{array}{l}L \\
(\mathrm{~m})\end{array}$ & $G T$ & $\begin{array}{l}t_{\mathrm{s}} \\
(\mathrm{m})\end{array}$ & $\begin{array}{l}S \\
(\mathbf{m})\end{array}$ \\
\hline $\begin{array}{l}4,5,6, \\
7,8\end{array}$ & $\begin{array}{l}10,20, \\
30,40\end{array}$ & IV & 0,20 & 2,4 \\
\hline $\begin{array}{l}4,5,6, \\
7,8\end{array}$ & 30 & $\begin{array}{l}\text { II, III, } \\
\text { IV, V }\end{array}$ & 0,20 & 2,4 \\
\hline $\begin{array}{l}4,5,6, \\
7,8\end{array}$ & 30 & IV & $\begin{array}{l}0,15,0,20 \\
0,25,0,30\end{array}$ & 2,4 \\
\hline $\begin{array}{l}4,5,6, \\
7,8\end{array}$ & 30 & IV & 0,20 & $\begin{array}{l}1,2,2,4, \\
3,6,4,8\end{array}$ \\
\hline
\end{tabular}

Bilginin ileriye doğru beslemesi

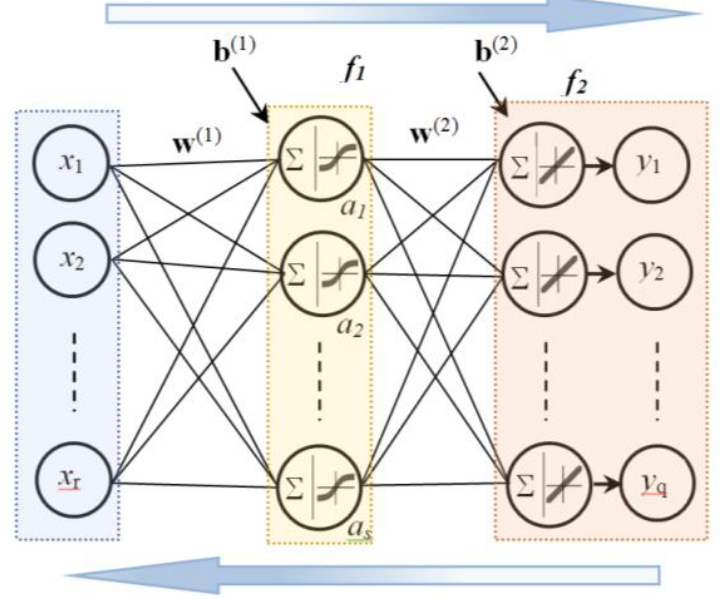

Hatalarm geriye doğru yayılması

Şekil 2. Yapay sinir ağı modeli 
Hem sinir ağları hem de makine öğrenmesi yöntemleri yapay zekâ ekosisteminin alt alanlarıdır. Derin öğrenme (deep learning) birkaç gizli katmandan oluşan sinir ağlarına verilen isimdir. Bu nedenle tek gizli katmana sahip olan sinir ağlarına "Sı̆̆ Sinir Ağları" da denilmektedir [21].

Sı ̆ sinir ağları genellikle girdi katmanı, gizli katman ve çıktı katmanı olmak üzere 3 katmandan oluşur (Şekil 2). Her bir katmanın içerisinde insan beynindeki nöronlardan esinlenilmiş dügüm olarak adlandırabileceğimiz noktalarda hesaplamalar yapılmaktadır. Girdi katmanı sinir ağının başlangıç katmanıdır ve burada dış dünyadaki bilgileri içeren girdi düğümleri bulunur. Bu katmandaki dügüumler pasif düğümlerdir ve girdi bilgilerini üzerinde herhangi bir işlem yapmadan gizli katmana gönderir. Gizli katmanın dış dünya ile bir bağlantısı yoktur ve sinir ağına özel bir katmandır. Gizli katmandaki her bir düğümde tüm girdilerin belirli ağırlık katsayılarıyla çarpımlarının toplamına yanlılık değerleri eklenir ve bir aktivasyon fonksiyonu aracılığ 1 ile tek bir sayıya dönüştürülerek çıktı katmanına gönderilir. Çıktı katmanı gizli katmandaki tüm düğümlerden değerleri alır ve bunların yeniden ağırlık katsayıları ile çarpımlarının toplamına yanlılık değerleri eklenir yeniden bir aktivasyon fonksiyonu ile çıktıları üretir. Çıktı katmanında yapay sinir ağı modelinin kaç çıktısı varsa o kadar dügüm bulunur. Gizli katman aslında girdiler ve çıktılar arasındaki bağlantıyı kuran katman gibi görünse de girdi ve çıtı arasındaki ilişkileri açık olarak görebilmek mümkün olmadığı için bazen kara kutu olarak da nitelendirilir. Gizli katmandaki düğüm sayısı deneme yanılma yoluyla, oluşan hataları minimize edecek şekilde belirlenebilir.

Sinir ağları mimarisindeki girdilerden çıktılara doğru yönelen ilerleme "ileri doğru besleme", diğer bir ifade ile ağ içinde doğru bilginin ileri beslenmesi, olarak adlandırılır (Şekil 2). Sinir ağının öğrenmesinin gerçekleştiği mekanizma ise "geriye doğru yayılma" olarak isimlendirilir. Bu yayılmada sinir ağının yaptığı tahminle gerçek değer arasındaki farkın bir fonksiyonu olan hata geriye doğru aktarılır. $\mathrm{Bu}$ aktarılan bilgi kullanılarak gizli katmanda ve çıktı katmanında bulunan düğümlerde kullanılan ağırlıklar ve yanlılık yeniden değerlendirilerek sinir ağının daha iyi bir tahmin yapmasına olanak sağlanır. Bu şekilde yapay sinir ağının, ileri ve geri doğru tekrar tekrar işlemesiyle hatanın minimize edilmesi sağlanarak, girdi ve çıktılar arasındaki bağlantıları öğrenilmesi gerçekleşir. Tüm girdilerin işlenmesiyle gerçekleşen her bir ileri-geri işlem adımı dönem (epoch) olarak adlandırılır. Her bir adımda ağırlıklar değişeceği için hata da değişecektir. Oluşan hatalar "kayıp fonksiyonu" olarak bilinir ve bu hatayı hesaplamak için farklı yöntemler vardır (hataların karesinin ortalaması (MSE), ortalama mutlak hata (MAE), vs.). Hatanın azaltılmasını sağlayacak şekilde parametrelerin değişimi ise optimizasyon yöntemleri (gradyan inişi, Levenberg-Marquardt yöntemi, Bayesian düzenlemesi, Newton yöntemi vs.) kullanılarak gerçekleştirilir. $\mathrm{Bu}$ yöntemler hata fonksiyonunun minimumunu bulmaya çalışan yöntemlerdir. $\mathrm{Bu}$ çalışmada "Bayesian düzenlemesi”" geriye yayılma öğrenme fonksiyonu kullanılmıştır.

Öğrenme süreci, düğüm noktası girdi verilerini bir takım ağırlık katsayıları ile bu girdinin etkisini artıracak veya azaltacak şekilde derecelendirerek ilişkilendirir. Böylelikle bu girdinin önemi belirlenmiş olur. Daha sonra tüm girdiler ilgili ağırlık katsayıları ile çarpılarak toplanır ve bir aktivasyon fonksiyonuna gönderilerek bu düğümdeki sinyalin ne ölçüde çıktı vereceği belirlenir. Şekil 3a'dan da görüleceği üzere bir insan sinir hücresindeki (nöron) dendrit denilen filamentler hücreye gelen sinyalleri almakta, hücre gövdesi (soma) alınan sinyalleri işleyerek akson denilen filamentler aracılığı ile oluşturduğu sinyalleri başka sinir hücrelerinin dendritlerine veya bir olay gerçekleştirecek olan kas veya salg1 hücreleri gibi diğer hücrelere aktarmaktadır. Şekil 3 b'den de görüleceği üzere, biyolojik sinir hücreleri ile yapı yapay sinir ağları birçok bakımdan birbirlerine benzemektedir. Dendritler girdileri, aksom uçları çıktıları ve hücre gövdesi de girdilerin ağırlıklarla çarpılarak toplamını ve aktivasyon fonksiyonunu temsil etmektedir. Ancak iki yapı arasındaki önemli farklar da vardır. Örneğin, yapay sinir ağları aldığı girdilere herhangi bir ağırlıkta tepki verebilirken, biyolojik sinir hücreleri aldığı sinyallere ya tepki verir ya da 
hiç tepki vermez. Bunun yanında, biyolojik sinir hücresinin tepki süresi $10^{-3} \mathrm{~s}$ iken, bir silikon devrenin tepki süresi ise $10^{-9} \mathrm{~s}$ gibi çok daha kısa bir sürede gerçekleşir. Yapay sinir hücresinin bu hızına karşılık biyolojik sistemler çok daha fazla sinir hücresine ve bağlantılarına sahiptir. İnsan beyni yaklaşık 86 milyar nöron içermektedir. Her bir nöronun diğer nöronlara ortalama 7000 sinaptik bağlantısı vardır. 3 yaşındaki bir çocuğun $1 * 10^{15}$ sinaptik bağlantısı olduğu tahmin edilmektedir [22].

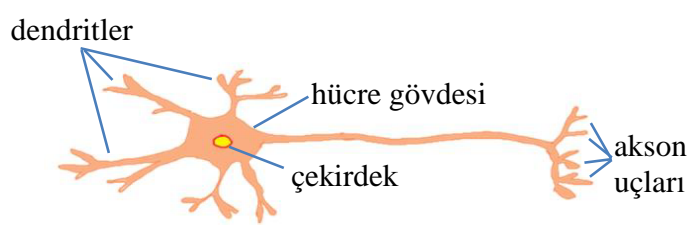

(a)



Şekil 3. (a) Biyolojik sinir hücresi (b) yapay sinir hücresi modeli

Sı ̆̆ yapay sinir ağları modellerinde genelde tek gizli katman olur. Gizli katman sayısının artırılması sinir ağının tahmin gücünü artırabilir. Ancak bu durumda da aşırı uyum (overfit) oluşabilir. Aşırı uyum sinir ağının girdiler ve çıktılar arasındaki genel yapıyı anlamaktan ziyade çok detaylı olarak ilişkileri öğrenmesinden kaynaklanır. $\mathrm{Bu}$ durumun genellikle eğitim verilerinin sayısının sinir ağ 1 modelinin karmaşıklığı yanında az olmasından kaynaklandığı tahmin edilebilir.

\subsection{HYDK Denklemlerini Bulmak İçin Kullanılan Sinir Ağları Mimarisi}

Bu çalışmada, elimizdeki problemin girdi, çıktı verileri ve karakteristik yapısı dikkate alındığında tek gizli katman kullanılmasının yeterli olacağı düşünülmektedir. Böylelikle, kullanılacak sinir ağı modeli girdi ve çıktı katmanları ile birlikte üç katmandan oluşacaktır (Şekil 4). Şekilden de görüleceği üzere, yapay sinir ağı modeli girdilerin ileriye doğru beslenmesini ve hataların geriye doğru yayılması ile öğrenmektedir. Hedef (gerçek) değer ile sinir ağının çıktısı (tahmini) arasındaki fark hatayı ifade etmektedir. Optimizasyon ve sinir ağları modellerinde birçok kayıp fonksiyonu kullanılsa da, yaygın olarak hataların karesinin ortalaması (MSE) kullanılmaktadır. Bu nedenle bu çalışmada da aşağıdaki gibi bir hataların karesinin ortalaması fonksiyonu (MSE) minimize edilmektedir (Eşitlik 2):

$M S E=\frac{1}{n} \sum_{i=1}^{n}\left(y_{i}-\hat{y}_{i}\right)^{2}$

$\mathrm{Bu}$ eşitlikteki $y_{i}$ tahmin edilen değerleri ve $\hat{y}_{i}$ de hedef değerleri ifade etmektedir. Çıktı katmanındaki çıktıları $\left(\mathrm{y}_{\mathrm{i}}\right)$ hesaplamak için önce gizli katmandaki her bir dügüumde oluşan değerler $\left(a_{k}\right)$ hesaplanır (Eşitlik 3).

$a_{k}=f_{1}\left(\sum_{j=1}^{r} w_{k j}^{(1)} \cdot x_{j}+b^{(1)}\right)$

Buradaki $\mathrm{w}_{\mathrm{kj}}^{(1)}$ girdi katmanındaki ağırlıkları; $\mathrm{x}_{\mathrm{j}}$ girdileri; $b^{(1)}$ yanlılık değerlerini (bias) ve $f_{1}($ ) gizli katmandaki aktivasyon fonksiyonunu (Şekil 4b) ifade eder. Elde edilen $a_{k}$ değerleri kullanılarak Eşitlik 4 aracılığı ile de çıktılar $\left(\mathrm{y}_{\mathrm{i}}\right)$ hesaplanır. $\mathrm{Bu}$ çalışmada tek bir nöron kullanıldığ 1 için $\mathrm{k}$ indisi sadece bir olacaktır. Ayrıca, tek bir nöron kullanıldığ 1 için her bir çıkt1 için (İçM1, İçM2 vs.) sinir ağı ayrı ayrı çalıştırılmıştır (Eşitlik 4).

$y_{i}=f_{2}\left[\sum_{k=1}^{s} w_{i k}^{(2)} \cdot a_{k}+b^{(2)}\right]$

Bu eşitlikteki $a_{k}$ gizli katmandaki her bir düğümde oluşan değerleri; $w_{j}^{(2)}$ girdi katmanındaki ağırlıkları; $b^{(2)}$ yanlılık değerlerini ve $f_{2}($ ) gizli katmandaki aktivasyon fonksiyonunu temsil eder. Sinir ağı eğitilirken, her bir işlem adımında (epoch) tüm ağırlıklar ve yanlılık değerleri kayıp fonksiyonunu minimize etmek için güncellenir. 

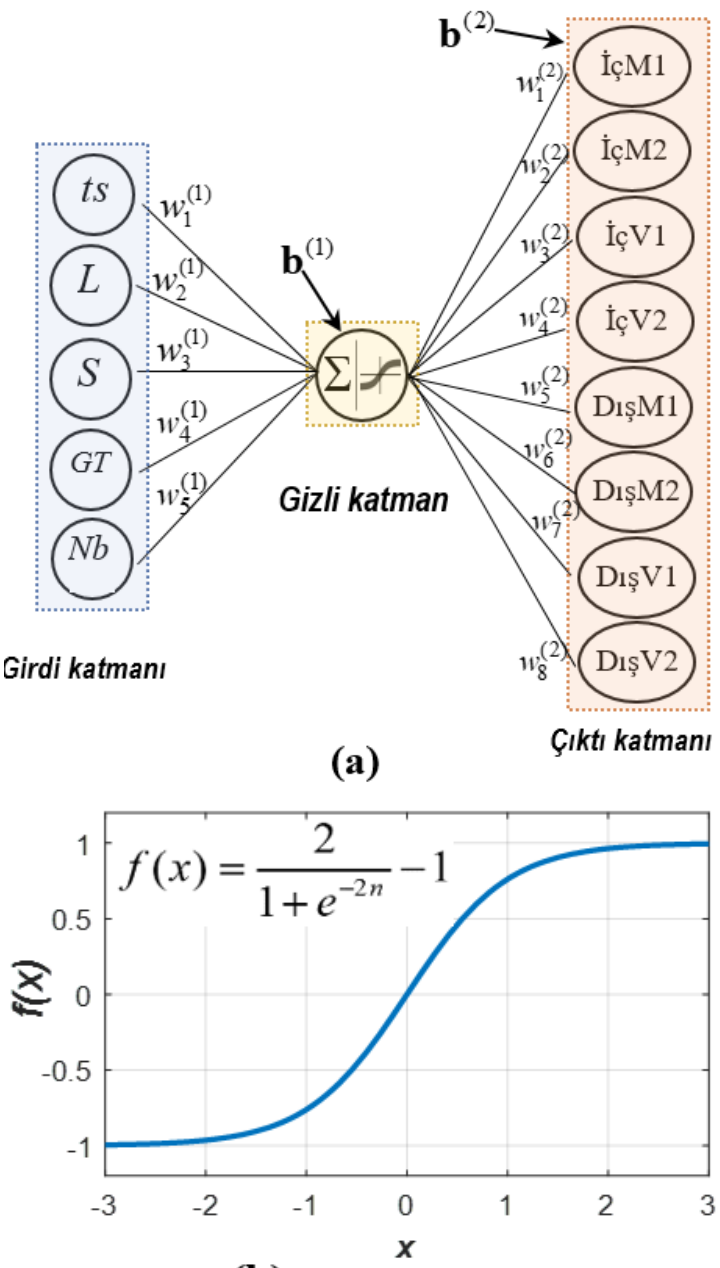

(b)

Şekil 4. (a) Kullanılan yapay sinir ağı mimarisi (b) Tansig fonksiyonu

Aktivasyon fonksiyonları göz önüne alınan problemin niteliğine (regresyon, sinıflandırma vs.) göre seçilebilir. Derin öğrenme yöntemlerinde ReLU (Rectified Linear Unit) fonksiyonu birden fazla gizli katmandan oluşan sinir ağının daha iyi öğrenmesini sağlasa da sığ sinir ağlarında genellikle tercih edilen fonksiyonlar doğrusal, sigmoid veya hiperbolik tanjant fonksiyonlarıdır [1]. Bu çalışmada da hassasiyet analizleri yapılarak sigmoid veya hiperbolik tanjant fonksiyonları arasında önemli bir fark oluşmadığı görülmüştür. $\mathrm{Bu}$ nedenle gizli katmanda hiperbolik tanjant (tansig) fonksiyonu ve çıktı katmanında da doğrusal (purelin) fonksiyonu kullanılmıștır (Şekil 2).

Bu çalışmada eğitim algoritması olarak "Bayesian Regularization" algoritması diğer yöntemlere göre daha iyi sonuç verdiği için tercih edilmiştir. Bu algortimanın daha güçlü olması ve doğrulama adımına gerek duymaması özelliklerinden dolayı da diğer araştırmacıların tercihi olmaktadır [23].

Çizelge 3'te bu çalışma için oluşturulan sinir ağ mimarisine ait parametrelerin değerleri verilmiştir. Yapay sinir ağında ele alınan girdiler Çizelge 2'de verilen üstyapı özellikleridir: tabliye kalınlığı (ts), köprü uzunluğu (L), kirişler arasındaki açıklık (S), kiriş tipi (GT) ve kiriş sayısı (Nb). Çizelge 2'den de görülebileceği gibi, her bir hareketli yük dağılım katsayısı türü için 65 adet birbirinden farklı girdi verisi bulunmaktadır. $\mathrm{Bu} 65$ veri setinin 56 tanesi sinir ağının eğitimi için ve 9 tanesi de sinir ağının test edilmesi için kullanılmıştır.

Sinir ağının tahmin edeceği çıktılar ise bir veya birden daha fazla kamyon yükleri altında iç kirişlerde oluşan hareketli yük dağılım katsayılarıdır (İçM1, İç M2, İçV1, İçV2, D1şM1, D1şM2, DışV1, D1şV2). Bu katsayıları ifade eden kısaltmalardaki "İç" ifadesi iç kirişi, Dış ifadesi dış kirişi, $\mathrm{M}$ ve $\mathrm{V}$ harfleri moment ve kesme kuvvetini, 1 ve 2 rakamları ise yüklemede kullanılan kamyonların 1 veya 1'den fazla olmas1 durumunu ifade etmektedir. Her bir girdi verisi seti 5 parametreye sahiptir ve her girdi setine karşılık 8 adet hareketli yük dağılım katsayısı içeren bir çıktı verisi seti bulunmaktadır.

Çizelge 3. YSA'nın mimari parametreleri

\begin{tabular}{|l|l|}
\hline Parametreler & Değerler \\
\hline Girdiler & ts, L, S, GT, Nb \\
\hline Çıktılar & $\begin{array}{l}\text { İçM1, İç2, İçV1, İçV2 } \\
\text { D1şM1,D1şM2, D1şV1, } \\
\text { DışV2 }\end{array}$ \\
\hline Kayıp fonksiyonu & MSE \\
\hline $\begin{array}{l}\text { Gizli Katman } \\
\text { aktivasyon fonksiyonu }\end{array}$ & Tansig \\
\hline $\begin{array}{l}\text { Çıktı Katmanı } \\
\text { aktivasyon fonksiyonu }\end{array}$ & Purelin \\
\hline Optimizasyon yöntemi & Bayesian regularization \\
\hline
\end{tabular}




\section{ANALIZZ SONUÇLARI}

Çalışma kapsamında oluşturulan yapay sinir ağ 65 adet farklı özelliklere sahip basit mesnetli köprü için HYDK'yi tahmin etmek için kullanılmıştır. Bu köprülerden 56 tanesi sinir ağını eğitmek için kullanılmış ve 9 tanesi de test için kullanılmıştır. Çizelge 4'te bu köprülere ait parametreler ve analiz sonuçlarından elde edilen HYDK verilmiştir. Yapay sinir ağının eğitim ve test aşamasındaki performansı kayıp fonksiyonu olan hataların karesinin ortalaması (MSE) cinsinden Çizelge 5'te verilmiştir. Çizelgeden de görüleceği gibi hatayı minimize etmek için farklı bileşenler için dönem sayıları 18-30 arasında değişmektedir. En büyük hata değerleri ise 3,35e-5-3,69e-4 arasında oluşmaktadır ve bu da göstermektedir ki sinir ağ 1 modeli oldukça iyi tahminler yapabilmektedir. Bunun yanı sıra, sinir ağının test ve eğitim performansları arasında belirgin bir farklılık gözlenmemektedir.

Yapay sinir ağının HYDK için yaptı̆̆ı tahminler ve sonlu elemanlar sonuçları tüm bileşenler için, Şekil 5 ve Şekil 6'da eğitim ve test değerleri için sırasıyla gösterilmiştir. Şekillerdeki HYDK-Hedef ekseni sonlu eleman sonuçlarını; HYDK-Tahmin ekseni ise sinir ağının tahminini temsil etmektedir. Şekillerden de görüleceği gibi, sinir ağ 1 modeli hem eğitim aşamasında hem de test aşamasında hedef olan sonlu elemanlar sonuçlarını kabul edilebilir düzeyde iyi tahmin edebilmiștir. Özellikle Şekil 4'deki test verilerinin karşılaştırması önemlidir, çünkü buradaki girdi verileri ile sinir ağı modeli hiç karşılaşmamıştır. $\mathrm{Bu}$ yeni girdi verilerinin sonuçlarının tahmini de oldukça iyi gerçekleştirilmiştir.

Bunlara ilave olarak, şekillerin içerisinde sonlu elemanlar sonuçlarının sinir ağı tahmin sonuçlarına oranı ile ilgili niceliksel ölçüt olarak bu oranların ortalaması (Mean) ve sonuçlar arasındaki ilişkiyi temsilen korelasyon katsayısı (R) gösterilmiştir. Oranların ortalamasını incelediğimizde değerlerin eğitim verileri için $0,99981,0002$ aralığında, test verileri içinse 0.9896-1.0095 aralığında olduğu görülmektedir. Korelasyon katsayısı değerleri açısından, eğitim verileri için en kötü ilişki 0,9808 ile DışM2 bileșeninde, en iyi ilişki ise 0,9984 ile İçV2 bileşeninde görülmektedir. Test verileri arasındaki en kötü korelasyon 0,9870 ile IntM2'de, en iyi korelasyon ise 0,9996 ile IntV2 bileşeninde oluşmaktadır. Test verileri için korelasyon değerlerinde eğitim verilerine göre önemli bir fark görünmemektedir. Ancak, oranların ortalamas 1 değerlerinin test verilerinde, eğitim verilerine göre, 1,0000 değerinden daha fazla saptı̆ 1 gözlenmektedir. Bunun nedeni ise sinir ağı modeli test verileri ile ilk defa karşılaşmışıtır. Tüm girdi değerleri için eğitim ve test verilerinin tamamı Çizelge 6'da AASHTO LRFD sonuçları ile karşılaştırmalı olarak gösterilmiştir.

Çizelge 4. Köprü parametreleri ve hareketli yük dağılım katsayıları

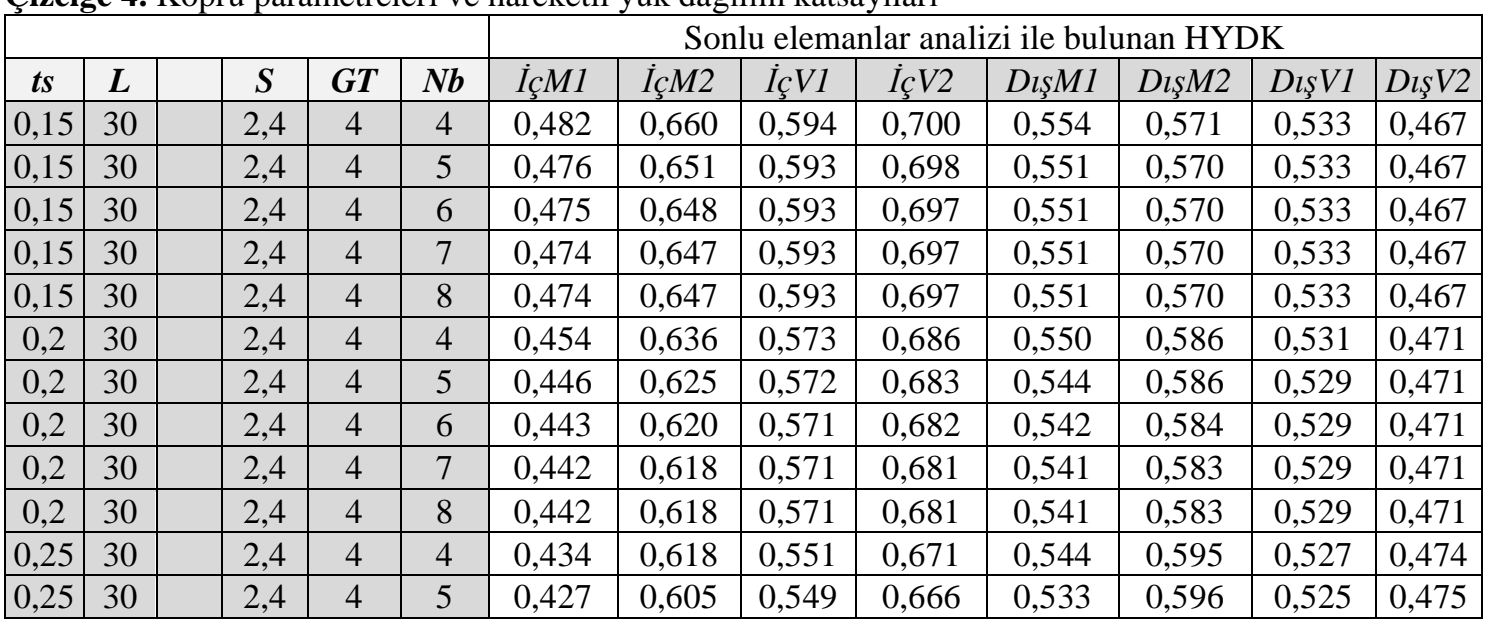




\begin{tabular}{|c|c|c|c|c|c|c|c|c|c|c|c|c|}
\hline 0,25 & 30 & 2,4 & 4 & 6 & 0,423 & 0,599 & 0,548 & 0,665 & 0,529 & 0,592 & 0,524 & 0,474 \\
\hline 0,25 & 30 & 2,4 & 4 & 7 & 0,421 & 0,596 & 0,548 & 0,664 & 0,528 & 0,590 & 0,523 & 0,474 \\
\hline 0,25 & 30 & 2,4 & 4 & 8 & 0,420 & 0,595 & 0,548 & 0,664 & 0,528 & 0,589 & 0,523 & 0,474 \\
\hline 0,3 & 30 & 2,4 & 4 & 4 & 0,423 & 0,605 & 0,529 & 0,654 & 0,534 & 0,597 & 0,523 & 0,477 \\
\hline 0,3 & 30 & 2,4 & 4 & 5 & 0,416 & 0,589 & 0,527 & 0,649 & 0,522 & 0,599 & 0,520 & 0,478 \\
\hline 0,3 & 30 & 2,4 & 4 & 6 & 0,410 & 0,584 & 0,525 & 0,646 & 0,515 & 0,594 & 0,518 & 0,477 \\
\hline 0,3 & 30 & 2,4 & 4 & 7 & 0,407 & 0,581 & 0,524 & 0,645 & 0,512 & 0,591 & 0,517 & 0,476 \\
\hline 0,3 & 30 & 2,4 & 4 & 8 & 0,406 & 0,579 & 0,524 & 0,645 & 0,511 & 0,590 & 0,517 & 0,476 \\
\hline 0,2 & 10 & 2,4 & 4 & 4 & 0,756 & 0,825 & 0,640 & 0,713 & 0,591 & 0,489 & 0,514 & 0,422 \\
\hline 0,2 & 10 & 2,4 & 4 & 5 & 0,756 & 0,826 & 0,640 & 0,714 & 0,591 & 0,489 & 0,514 & 0,422 \\
\hline 0,2 & 10 & 2,4 & 4 & 6 & 0,756 & 0,826 & 0,640 & 0,714 & 0,591 & 0,489 & 0,514 & 0,422 \\
\hline 0,2 & 10 & 2,4 & 4 & 7 & 0,756 & 0,826 & 0,640 & 0,714 & 0,591 &, 489 & 0,514 & 0,422 \\
\hline 0,2 & 10 & 2,4 & 4 & 8 & 0,756 & 0,826 & 0,640 & 0,714 & 0,591 &, 489 & 0,514 & 0,422 \\
\hline 0,2 & 20 & 2,4 & 4 & 4 & 0,542 & 0,712 & 0,589 & 0,699 & 0,585 &, 554 & 0,532 & 0,458 \\
\hline 0,2 & 20 & 2,4 & 4 & 5 & 0,538 & 0,706 & 0,588 & 0,697 &, 584 & 554 & 532 & 0,458 \\
\hline 0,2 & 20 & 2,4 & 4 & 6 & 0,537 & 0,704 & 0,588 & 0,697 &, 584 & 554 & 532 & 0,458 \\
\hline 0,2 & 20 & 2,4 & 4 & 7 & 0,537 & 0,704 & 0,588 & 0,697 & 0,584 & 0,554 & 0,532 & 0,458 \\
\hline 0,2 & 20 & 2,4 & 4 & 8 & 0,537 & 0,704 & 0,588 & 0,697 & 0,584 & 0,554 & 0,532 & 0,458 \\
\hline 0,2 & 40 & 2,4 & 4 & 4 & 0,421 & 0,605 & 0,565 & 0,681 & 0,515 & 0,585 & 0,528 & 0,474 \\
\hline 0,2 & 40 & 2,4 & 4 & 5 & 0,413 & 0,586 & 0,563 & 0,676 & 0,505 & 0,585 & 0,526 & 0,475 \\
\hline 0,2 & 40 & 2,4 & 4 & 6 & 0,408 & 0,581 & 0,562 & 0,674 & 0,499 & 0,580 & 0,525 & 0,474 \\
\hline 0,2 & 40 & 2,4 & 4 & 7 & 0,406 & 0,578 & 0,562 & 0,674 & 0,497 & 0,577 & 0,524 & 0,474 \\
\hline 0,2 & 40 & 2,4 & 4 & 8 & 0,405 & 0,576 & 0,562 & 0,673 & 0,496 & 0,576 & 0,524 & 0,473 \\
\hline 0,2 & 30 & 2,4 & 2 & 4 & 0,414 & 0,597 & 0,532 & 0,654 & 0,520 & 0,594 & 0,525 & 0,481 \\
\hline 0,2 & 30 & 2,4 & 2 & 5 & 0,406 & 0,577 & 0,530 & 0,647 & 0,509 & 0,594 & 0,522 & 0,482 \\
\hline 0,2 & 30 & 2,4 & 2 & 6 & 0,400 & 0,576 & 0,527 & 0,645 & 0,502 & 0,589 & 0,520 & 0,481 \\
\hline 0,2 & 30 & 2,4 & 2 & 7 & 0,397 & 0,573 & 0,526 & 0,645 & 0,499 & 0,586 & 0,519 & 0,481 \\
\hline 0,2 & 30 & 2,4 & 2 & 8 & 0,396 & 0,571 & 0,526 & 0,644 & 0,498 & 0,584 & 0,519 & 0,480 \\
\hline 0,2 & 30 & 2,4 & 3 & 4 & 0,433 & 0,618 & 0,557 & 0,673 & 0,540 & 0,593 & 0,529 & 0,475 \\
\hline 0,2 & 30 & 2,4 & 3 & 5 & 0,426 & 0,604 & 0,555 & 0,669 & 0,531 & 0,593 & 0,527 & 0,476 \\
\hline 0,2 & 30 & 2,4 & 3 & 6 & 0,421 & 0,598 & 0,553 & 0,668 & 0,527 & 0,589 & 0,525 & 0,475 \\
\hline 0,2 & 30 & 2,4 & 3 & 7 & 0,419 & 0,594 & 0,552 & 0,667 & 0,525 & 0,588 & 0,525 & 0,475 \\
\hline 0,2 & 30 & 2,4 & 3 & 8 & 0,419 & 0,593 & 0,552 & 0,666 & 0,525 & 0,587 & 0,525 & 0,474 \\
\hline 0,2 & 30 & 2,4 & 5 & 4 & 0,474 & 0,654 & 0,586 & 0,696 & 0,568 & 0,584 & 0,535 & 0,468 \\
\hline 0,2 & 30 & 2,4 & 5 & 5 & 0,467 & 0,645 & 0,584 & 0,694 & 0,563 & 0,584 & 0,534 & 0,468 \\
\hline 0,2 & 30 & 2,4 & 5 & 6 & 0,465 & 0,641 & 0,580 & 0,693 & 0,562 & 0,582 & 0,533 & 0,468 \\
\hline 0,2 & 30 & 2,4 & 5 & 7 & 0,464 & 0,640 & 0,580 & 0,692 & 0,562 & 0,582 & 0,533 & 0,468 \\
\hline 0,2 & 30 & 2,4 & 5 & 8 & 0,464 & 0,640 & 0,580 & 0,692 & 0,562 & 0,582 & 0,533 & 0,468 \\
\hline 0,2 & 30 & 1,2 & 4 & 4 & 0,322 & 0,000 & 0,414 &, 000 & 0,376 & 0,000 & 0,394 & 0,000 \\
\hline 0,2 & 30 & 1,2 & 4 & 5 & 0,300 & 0,000 & 0,407 & 0,000 & 368 & 0,000 & 0,393 & 0,000 \\
\hline 0,2 & 30 & 1,2 & 4 & 6 & 0,294 & 0,353 & 0,404 & 0,414 & 0,363 & 0,364 & 0,392 & 0,336 \\
\hline 0,2 & 30 & 1,2 & 4 & 7 & 0,290 & 0,340 & 0,403 & 0,411 & 0,360 & 0,369 & 0,392 & 0,338 \\
\hline 0,2 & 30 & 1,2 & 4 & 8 & 0,289 & 0,336 & 0,403 & 0,411 & 0,358 & 0,370 & 0,391 & 0,338 \\
\hline 0,2 & 30 & 3,6 & 4 & 4 & 0,573 & 0,905 & 0,719 & 0,926 & 0,680 & 0,759 & 0,648 & 0,600 \\
\hline 0,2 & 30 & 3,6 & 4 & 5 & 0,567 & 0,894 & 0,718 & 0,924 & 0,678 & 0,757 & 0,647 & 0,599 \\
\hline
\end{tabular}




\begin{tabular}{|l|l|l|l|l|l|l|l|l|l|l|l|l|}
\hline 0,2 & 30 & 3,6 & 4 & 6 & 0,566 & 0,891 & 0,718 & 0,923 & 0,678 & 0,757 & 0,647 & 0,599 \\
\hline 0,2 & 30 & 3,6 & 4 & 7 & 0,566 & 0,891 & 0,718 & 0,923 & 0,678 & 0,757 & 0,647 & 0,599 \\
\hline 0,2 & 30 & 3,6 & 4 & 8 & 0,566 & 0,891 & 0,718 & 0,923 & 0,678 & 0,757 & 0,647 & 0,599 \\
\hline 0,2 & 30 & 4,8 & 4 & 4 & 0,691 & 1,157 & 0,826 & 1,119 & 0,780 & 0,908 & 0,734 & 0,738 \\
\hline 0,2 & 30 & 4,8 & 4 & 5 & 0,687 & 1,150 & 0,825 & 1,117 & 0,780 & 0,907 & 0,734 & 0,738 \\
\hline 0,2 & 30 & 4,8 & 4 & 6 & 0,687 & 1,150 & 0,825 & 1,117 & 0,780 & 0,907 & 0,734 & 0,738 \\
\hline 0,2 & 30 & 4,8 & 4 & 7 & 0,687 & 1,149 & 0,825 & 1,117 & 0,780 & 0,907 & 0,734 & 0,738 \\
\hline 0,2 & 30 & 4,8 & 4 & 8 & 0,687 & 1,149 & 0,825 & 1,117 & 0,780 & 0,907 & 0,734 & 0,738 \\
\hline
\end{tabular}

Çizelge 5. Eğitim ve test performansları

\begin{tabular}{|c|c|c|c|}
\hline Bileşen & $\begin{array}{c}\text { Eğitim } \\
\text { Performansı } \\
\text { (MSE) }\end{array}$ & $\begin{array}{c}\text { Test } \\
\text { Performansı } \\
\text { (MSE) }\end{array}$ & $\begin{array}{c}\text { Dönem } \\
\text { Sayısı } \\
\text { (epoch) }\end{array}$ \\
\hline İçM1 & $8,51 \mathrm{E}-05$ & $1,02 \mathrm{E}-04$ & 30 \\
\hline İçM2 & $1,95 \mathrm{E}-04$ & $3,69 \mathrm{E}-04$ & 22 \\
\hline İçV1 & $3,35 \mathrm{E}-05$ & $2,82 \mathrm{E}-05$ & 30 \\
\hline İçV2 & $9,84 \mathrm{E}-04$ & $7,25 \mathrm{E}-05$ & 18 \\
\hline DışM1 & $9,84 \mathrm{E}-05$ & $4,06 \mathrm{E}-05$ & 22 \\
\hline D1şM2 & $2,59 \mathrm{E}-04$ & $1,67 \mathrm{E}-04$ & 19 \\
\hline D1şV1 & $1,23 \mathrm{E}-04$ & $7,01 \mathrm{E}-05$ & 24 \\
\hline D1şV2 & $7,05 \mathrm{E}-05$ & $6,97 \mathrm{E}-05$ & 22 \\
\hline
\end{tabular}

\subsection{Kapalı Formda HYDK Formülleri}

Bu bölümde hem iç hem de dış kirişlerdeki eğilme momenti ve kesme kuvveti denklemleri kapalı formda elde edilecektir. Denklemlerin basit formda kalmaları için gizli katmanda tek bir düğüm alınmıştır. Ancak, tek bir düğüm alınmasına rağmen, Çizelge 5'te de görüleceği gibi hatalar oldukça düşük kalmaktadır. Sinir ağının eğitilmesinin ardından oluşan ağırlıklar ve yanlılık katsayıları aktivasyon fonksiyonu içerisine yazılarak kapalı formda eğilme momenti ve kesme kuvveti için HYDK'yı veren denklemler Eşitlik 5'te gösterildiği şekilde elde edilmişlerdir.
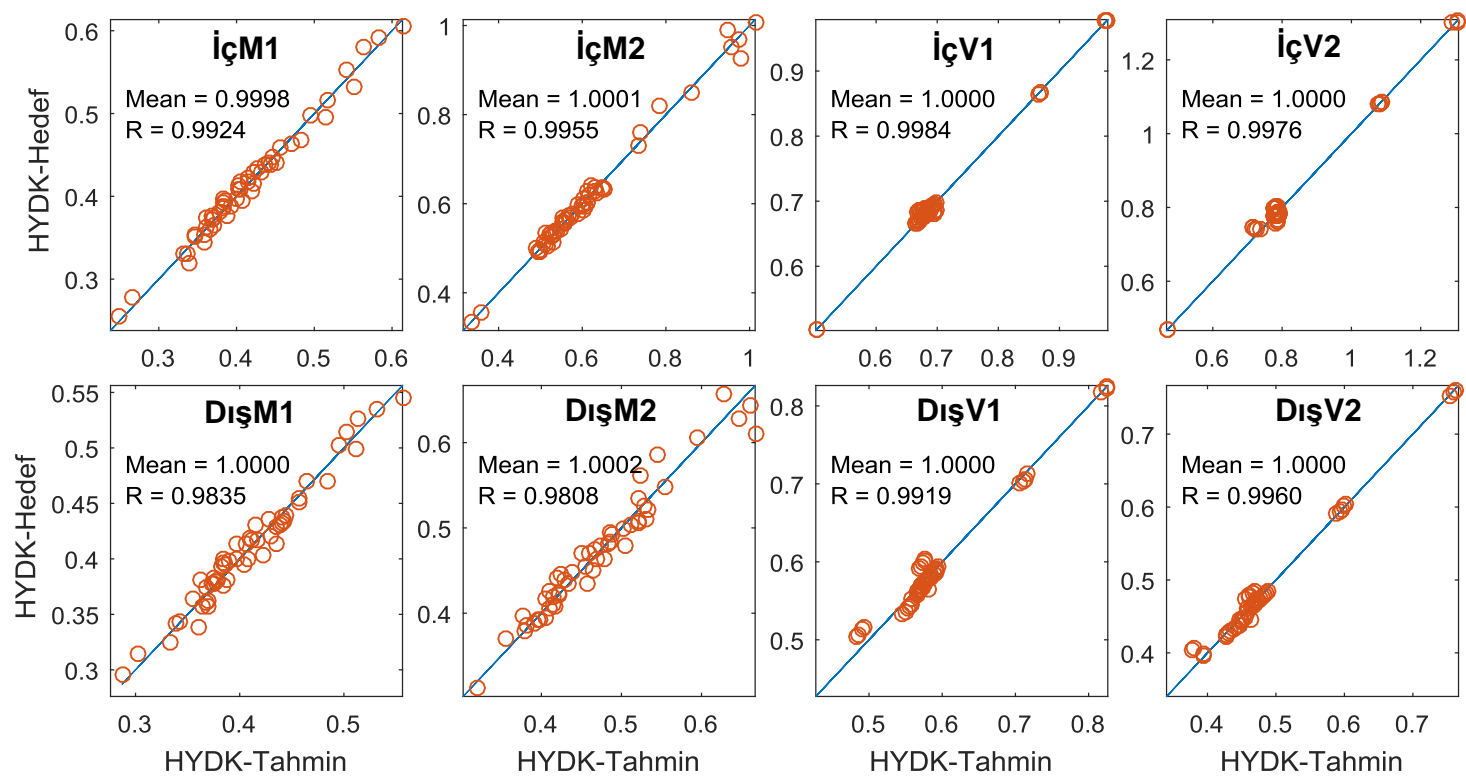

Şekil 5. Eğitim için kullanılan tahmin edilen ve sonlu eleman analizi ile elde edilen HYDK'nın karşılaştırılması 



Şekil 6. Test için kullanılan tahmin edilen ve sonlu eleman analizi ile elde edilen HYDK'nın karşılaştırılması

$$
\begin{aligned}
& \text { IçM1 }=\left[\frac{2}{1+e^{(-2(0,8722 t s+0,0066 ~ L-0,1854 S-0,0097 G T+0,415 N b-0,4872)}}-1\right](-0,5631)+0,2073 \\
& \text { İçM2 }=\left[\frac{2}{1+e^{(-2(0,3239 t s+0,0004 L-0,3653 S-0,0127 G T+0,0612 N b-0,5058)}}-1\right](-0,5348)+0,6295 \\
& \dot{\mathrm{I}} \mathrm{V} \mathrm{V} 1=\left[\frac{2}{1+e^{(-2(0,4457 t s-0,0004 L-0,4325 S-0,0167 G T-0,0035 N b+1,0228)}}-1\right](-0,3836)+0,6757 \sum \\
& \text { İçV2 }=\left[\frac{2}{1+e^{(-2(-0,0144 t s-0,0023 L-0,3166 S+0,0008 G T-0,0021 N b+0,7739)}}-1\right](-0,8518)+0,7252 \\
& \text { DışM1 }=\left[\frac{2}{1+e^{(-2(-0,1567 t s+0,0063 L+0,2531 S-0,0795 G T-0,0693 N b+0,1883)}}-1\right](-0,2776)+0,3371 \\
& \mathrm{D} \text { \̧M } 2=\left[\frac{2}{1+e^{(-2(-0,2869 t s-0,0075 L-0,3835 S+0,0914 G T+0,1109 N b+0,2259)}}-1\right](-0,2642)+0,4591 \\
& \mathrm{D} \text { ışV1 }=\left[\frac{2}{1+e^{(-2(+0,2140 t s+0,0044 L+0 ., 1828 S-0,0146 G T+0,0049 N b-0.4)}}-1\right](0,6880)+0,4444 \\
& \mathrm{D} \text { şV1 }=\left[\frac{2}{1+e^{(-2(+0,3911 t s+0,0050 L+0,2035 S-0,0246 G T+0,0051 N b-1,1458)}}-1\right](0,6832)+0,7655
\end{aligned}
$$


AASHTO LRFD'de basit mesnetli köprüler için hareketli yük denklemleri elde edilirken veya Dicleli ve Erhan'ın [24] integral köprüler için hazırladıkları hareketli yük denklemlerinde, parametrelerin formül içerisinde oluşturdukları form için bazı eğilim ve hassasiyet analizleri yapılması gerekmektedir. Ancak bu çalışmada elde edilen denklemler için böyle bir hazırlığa gerek kalmamıştır. Ayrıca, bu çalışmada elde edilen denklemlerin yapısında bulunan ağırlık çarpanları incelenerek hangi parametrenin hangi bileşen için ne kadar etkili olduğu doğrudan gözlenebilmektedir.

Çizelge 6. İç kirişler için yapay sinir ağından elde edilen moment ve kesme kuvveti harketli yük dağılım katsayılarının hedef verilerle (sonlu elemanlar analiz sonuçları)ve AASHTO denklemleri sonuçları ile karşılaştırılması

\begin{tabular}{|c|c|c|c|c|c|c|c|c|c|c|}
\hline \multirow{3}{*}{ İçM1 } & YSA & 0,3417 & 0,4018 & 0,5663 & 0,4208 & 0,3078 & 0,3494 & 0,4573 & 0,4813 & 0,4778 \\
\hline & SEA & 0,3481 & 0,3920 & 0,5502 & 0,4302 & 0,3207 & 0,3583 & 0,4708 & 0,4812 & 0,4782 \\
\hline & AASHTO & 0,4230 & 0,4858 & 0,7217 & 0,6921 & 0,4239 & 0,4414 & 0,5020 & 0,6010 & 0,6921 \\
\hline \multirow{3}{*}{ İçM2 } & YSA & 0,7922 & 0,5232 & 0,5656 & 0,5892 & 0,5003 & 0,5044 & 0,4841 & 0,5465 & 0,6094 \\
\hline & SEA & 0,7408 & 0,5176 & 0,5507 & 0,6081 & 0,5050 & 0,5071 & 0,4826 & 0,5422 & 0,6117 \\
\hline & AASH & 0,8925 & 0,6303 & 0,7425 & 0,6928 & 0,6660 & 0,8968 & 0,6031 & 0,6031 & 0,5863 \\
\hline \multirow{3}{*}{ İçV1 } & YSA & 0,6884 & 0,6855 & 0,6743 & 0,6765 & 0,9771 & 0,6684 & 0,8642 & 0,6870 & 0,6811 \\
\hline & SEA & 0,6798 & 0,6865 & 0,6740 & 0,6775 & 0,9757 & 0,6679 & 0,8633 & 0,6784 & 0,6711 \\
\hline & AASH & 0,6758 & 0,6758 & 0,6758 & 0,6758 & 0,9916 & 0,6758 & 0,8337 & 0,6758 & 0,6758 \\
\hline \multirow{3}{*}{ İçV2 } & YSA & 0,7789 & 0,7825 & 0,7622 & 1,3038 & 0,7855 & 1,3019 & 0,7825 & 0,7863 & 0,7838 \\
\hline & SEA & 0,7826 & 0,7883 & 0,7848 & 1,3075 & 0,7893 & 1,3023 & 0,7841 & 0,7910 & 0,7902 \\
\hline & AASH & 0,8164 & 0,8164 & 0,8164 & 1,3321 & 0,8164 & 1,3321 & 0,8164 & 0,8164 & 0,8164 \\
\hline \multirow{3}{*}{ DışM1 } & YSA & 0,4481 & 0,3616 & 0,4156 & 0,4115 & 0,3996 & 0,3557 & 0,2767 & 0,4850 & 0,4555 \\
\hline & SEA & 0,4476 & 0,3485 & 0,4095 & 0,4025 & 0,3923 & 0,3592 & 0,2760 & 0,4832 & 0,4530 \\
\hline & AASHTO & 0,6000 & 0,6000 & 0,6000 & 0,6000 & 0,6000 & 0,6000 & 0,4500 & 0,7500 & 0,7500 \\
\hline \multirow{3}{*}{ DişM2 } & YSA & 0,4124 & 0,3664 & 0,3342 & 0,3529 & 0,4526 & 0,5215 & 0,4982 & 0,4649 & 0,4346 \\
\hline & SEA & 0,3972 & 0,3795 & 0,3444 & 0,3605 & 0,4441 & 0,5141 & 0,4811 & 0,4545 & 0,4547 \\
\hline & AASHTO & 0,6283 & 0,5842 & 0,3635 & 0,7866 & 0,5290 & 0,5142 & 0,5512 & 0,5413 & 0,7866 \\
\hline \multirow{3}{*}{ DışV1 } & YSA & 0,5103 & 0,5561 & 0,5817 & 0,8209 & 0,5818 & 0,5554 & 0,5767 & 0,5754 & 0,7095 \\
\hline & SEA & 0,4883 & 0,5622 & 0,5852 & 0,8216 & 0,5834 & 0,5616 & 0,5800 & 0,5780 & 0,7159 \\
\hline & AASH & 0,6000 & 0,6000 & 0,6000 & 0,9000 & 0,6000 & 0,6000 & 0,6000 & 0,6000 & 0,7500 \\
\hline \multirow{3}{*}{ DışV2 } & YSA & 0,4004 & 0,7641 & 0,4521 & 0,4600 & 0,4577 & 0,3400 & 0,4763 & 0,4363 & 0,4204 \\
\hline & SEA & 0,3777 & 0,7656 & 0,4554 & 0,4612 & 0,4568 & 0,3430 & 0,4792 & 0,4425 & 0,4267 \\
\hline & AASHTO & 0,5714 & 0,9325 & 0,5714 & 0,5714 & 0,5714 & 0,3645 & 0,5714 & 0,5714 & 0,5714 \\
\hline
\end{tabular}

Sinir ağının öğrenmesi sonucu bulunan kapalı formda elde edilen denklemler, AASHTO LRFD'de verilen denklemlerle test için kullanılan girdiler (9 adet) kullanılarak karşılaştırılmıș ve Çizelge 6'da verilmiştir. Çizelgede ayrıca, hedef çıktı olarak kullanılan sonlu elemanlar sonuçları da gösterilmiştir. Sonuçlar karşılaştırıldığında sinir ağının oldukça iyi tahminler yaptığı görülmektedir.

\section{SONUÇLAR}

$\mathrm{Bu}$ çalışmada yapay sinir ağları kullanılarak hareketli yüklerin yarattığı moment ve kesme kuvveti etkilerinin basit mesnetli köprü kirişleri üzerindeki dağılımını temsil eden denklemler elde edilmiştir. Bu amaçla ilk olarak farklı yapısal parametrelere sahip 65 farklı köprü için HYDK sonlu eleman analizleri ile elde edilmiştir. Akabinde, kurulan bir yapay sinir ağına yapısal parametreler girdi olarak, HYDK da hedef veriler olarak girilmiş ve sinir ağı eğitilerek ağırlık ve yanlılık katsayıları elde edilmiştir. Sinir ağının sonuçları incelendiğinde hem eğitim hem de test verileri için tahmin edilen HYDK'nın sonlu elemanlar analiz sonuçlarına oldukça yakın olduğu görülmektedir. Elde edilen sonuçlar, tahmin edilen HYDK'nın hedef HYDK' na oranlarının ortalaması ve tahmin ile hedef değerler arasındaki korelasyon 
katsayıları da iç ve dış kirişlerdeki kesme ve moment HYDK için incelenmiştir. Bulunan ortalama değerlerinin ve korelasyon katsayılarının birim değere çok yakın olması sinir ağının köprü parametreleri arasındaki ilişkiyi çok iyi öğrendiğini göstermektedir. Ayrıca sinir ağının eğitimi esnasındaki performansını gösteren kayıp fonksiyonunun da çok küçük değerlere sahip olması sinir ağının yapacağı tahminlerin doğruluğunun göstergesidir. Bunlara ilave olarak, sinir ağının tahminleri ile AASHTO sonuçları karşılaştırıldığında yakın sonuçlar bulunmuştur. Elde edilen ağırlık katsayıları ve yanlılık değerleri aktivasyon fonksiyonu olarak kullanılan tansig fonksiyonuna konularak kapalı formda hareketli yük dağılımı denklemleri elde edilmiştir. $\mathrm{Bu}$ denklemler, köprü tasarım mühendislerine hareketli yük dağılım katsayılarını bulmak için kullanabilecekleri, köprü kiriş sayısını da $(\mathrm{Nb})$ içeren, en güncel formülleri sunmaktadır. Ayrıca, bu çalışma göstermiştir ki, yapay sinir ağları köprülerdeki hareketli yük etkilerini tahmin etmek için kullanılabilecek uygun bir yöntemdir ve farklı türdeki köprüler için de kullanılabilir.

\section{KAYNAKLAR}

1. LeCun, Y., Bengio, Y., Hinton, G., 2015. Deep Learning. Nature, 521(7553), 436-444.

2. Tshitoyan, V., Dagdelen, J., Weston, L., Dunn, A., Rong, Z., Kononova, O., Jain, A., 2019. Unsupervised Word Embeddings Capture Latent Knowledge from Materials Science Literature. Nature, 571(7763), 95-98.

3. Moayedi, H., Mosallanezhad, M., Rashid, A.S.A., Jusoh, W.A.W., Muazu, M.A., 2018. A Systematic Review and Meta-Analysis of Artificial Neural Network Application in Geotechnical Engineering: Theory and Applications. Neural Computing and Applications, 1-24.

4. Shahin, M.A., Jaksa, M.B., Maier, H.R., 2001. Artificial Neural Network Applications in Geotechnical Engineering. Australian Geomechanics, 36(1), 49-62.

5. Salehi, H., Burgueno, R., 2018. Emerging Artificial Intelligence Methods in Structural
Engineering. Engineering Structures, 171, 170-189.

6. Ng C-T., 2014. On the Selection of Advanced Signal Processing Techniques for Guided Wave Damage Identification Using a Statistical Approach. Engineering Structures, 67, 50-60.

7. Akbas, B., Doran, B., Alacali, S., Akşar, B., 2016. Estimating Stiffness Modification Factor for the Coupling Beam of Coupled Shear Walls Using a Neural Network Model. Karaelmas Science \& Engineering Journal, 6(2), 273-282.

8. Chen, G., Li, T., Chen, Q., Ren, S., Wang, C., Li, S., 2019. Application of Deep Learning Neural Network to Identify Collision Load Conditions Based on Permanent Plastic Deformation of Shell Structures. Computational Mechanics, 64(2), 435-449.

9. Mazanoğlu, K., Kandemir-Mazanoğlu, E.Ç., 2017. Çatlaklı Kirişlerin Yapay Sinir Ağları ile Modellenmesi. Afyon Kocatepe Üniversitesi Fen ve Mühendislik Bilimleri Dergisi, 17(3), 1129-1135.

10. Mansour, M.Y., Dicleli, M., Lee, J.Y., Zhang, J., 2004. Predicting the Shear Strength of Reinforced Concrete Beams Using Artificial Neural Networks. Engineering Structures, 26(6), 781-799.

11. Falcone, R., Lima, C., Martinelli, E., 2020. Soft Computing Techniques in Structural and Earthquake Engineering: a Literature Review. Engineering Structures, 207, 110269.

12. Xiao, F., Fan, J., Chen, G.S., Hulsey, J.L., 2019. Bridge Health Monitoring and Damage Identification of Truss Bridge Using Strain Measurements. Advances in Mechanical Engineering, 11(3), 1687814019832216.

13. Salomon, A.L., Wells, J., 2018. Exploiting Imagery Data Collected with Unmanned Aircraft Systems (UAS) for Bridge Inspections (No. 18-03134).

14. Gupta, R.K., Kumar, S., Patel, K.A., Chaudhary, S., Nagpal, A.K., 2015. Rapid Prediction of Deflections in Multi-span Continuous Composite Bridges Using Neural Networks, International Journal of Steel Structures, 15(4), 893-909.

15. Fahmy, A.S., El-Madawy, M. E. T., Gobran, Y. A., 2016. Using Artificial Neural Networks in the Design of Orthotropic Bridge Decks. 
Alexandria Engineering Journal, 55(4), 3195-3203.

16. Xu, G., Chen, Q., Chen, J., 2018. Prediction of Solitary Wave Forces on Coastal Bridge Decks Using Artificial Neural Networks. Journal of Bridge Engineering, 23(5), 04018023.

17. AASHTO LRFD, 2017. AASHTO LRFD Bridge Design Specifications. $8^{\text {th }}$ ed. Washington, DC: American Association of State Highway and Transportation Officials.

18. Zokaie, T., Osterkamp, T.A., Imbsen, R.A., 1991. Distribution of Wheel Loads on Highway Bridges, NCHRP 12-26 Final Rep., National Cooperative Highway Research Program, Washington, D.C.

19. Yalcin, O.F., Dicleli, M., 2013. Comparative Study on the Effect of Number of Girders on Live Load Distribution in Integral Abutment and Simply Supported Bridge Girders. Advances in Structural Engineering, 16(6), 1011-1034.

20.SAP2000, 2016. Integrated Finite Element Analysis and Design of Structures, Computers and Structures Inc., Berkeley, CA, USA.

21. Kim, P., 2017. Matlab Deep Learning with Machine Learning, Neural Networks and Artificial Intelligence, Apress, Berkeley.

22. Cooper, D.C., 2011. Introduction to Neuroscience. Donald C. Cooper Ph. D..

23. Burden, F., Winkler D., 2008. Bayesian Regularization of Neural Networks. in: Livingstone D.J. (eds) Artificial Neural Networks. Methods in Molecular Biology, vol 458. Humana Press.

24. Dicleli, M., Erhan, S., 2009. Live Load Distribution Formulas for Single-Span Prestressed Concrete Integral Abutment Bridge Girders. Journal of Bridge Engineering, 14(6), 472-486. 